\title{
НЕСОВРЕМЕННАЯ СТРАНА ВЛАДИСЛАВА ИНОЗЕМЦЕВА
}

Аннотация. Автор размышляет на тему противоречивого развития России в координатах современности - несовременности на основе исследования В.Л. Иноземщева, основателя Центра исследований постиндустриального общества. В статье акцентируется внимание на тех социокультурных и экономических параметрах, которые в значительной степени сегодня тормозят движение России к информачионным реалиям: речь, прежде всего, идёт о ресурсной экономике, архаично-традиционном понимании роли территорий, инновачионных стратегий и недоразвитии индустриального уклада. Размышления о страновой несовременности при этом неотделимь от полемики с исследователем по вопросам, касающиися дефи-ниций и особенностей национальных модернизаций, вне которых невозможны прочессы эффективного развития современного общества $u$ нарастание технологичности последнего в постиндустриальный период.

Ключевые слова: Россия, несовременная страна, ресурсная экономика, эффективность, противоречия модернизации, постиндустриализм.

Сегодня неангажированная часть российского интеллектуального социума с тревогой не только констатирует, но и - что куда важнее - пытается понять причины стремительного перехода нашей страны от установок и ценностей модерна к многочисленным, пусть пока и разрозненным, фрагментам архаики. Такое постижение даётся нелегко и поэтому достаточно часто сводится к сугубо публицистическим текстам, звучащим ярко, но редко глубоко аргументированно. Однако есть и другие примеры работ, в которых ответы на важнейшие россий-ские вызовы ищутся, базируясь, прежде всего, на междисциплинарных теоретических пост-роениях. Одна из таких попыток оказалась реализована в недавно вышедшей в издательстве «Альпина Паблишер» книге профессора В.Л. Иноземцева «Несовременная страна. Россия в мире XXI века» ${ }^{1}$. Задача, которую ставит перед собой автор, звучит предельно конкретно и обозначена в исследовании как процесс смещения акцента с оценок «ненормальности» страны, присутствующих сегодня во многих, особенно выходящих за рубежом работах, на постижение комплекса причин её «несовременности».

Иноземцев рассматривает отечественные реалии как минимум в трёх измерениях: социокультурном, социально-философском и экономическом, т.е. именно так, как они традиционно излагаются в работах теоретиков постиндустриализма. В.Л. Иноземцев безусловно, одна из ведущих фигур среди отечественных специалистов по постиндустриализму уже фактически третье десятилетие. Несмотря на перипетии своей профессиональной биографии, од-на структура присутствует в его деятельности неизменно:

(C) Водопьянова Елена Викторовна - доктор философских наук, профессор, главный научный сотрудник, руководитель Центра культурологии Отдела социально-политических исследований Института Европы РАН. Aдpec: 125009, Россия, Москва, ул. Моховая, д. 11, стр. 3. E-mail: veritas-41@yandex.ru.

DOI: http://dx.doi.org/10.15211/vestnikieran4201999103

1 Иноземцев В.Л. Несовременная страна. Россия в мире XXI века. M., $2018 . \quad$ URL: http://www.litres.ru/pages/biblio_book/?art=36633772\&lfrom=30440123 (дата обращения: 15.04.2019). 
речь идёт о Центре исследований постиндустриального общества, который был им основан в 1996 г. Можно заметить, что спектр нынешних исследовательских интересов профессора Иноземцева характеризуется дедуктивной эволюцией движения от общих, в том числе социально-философских, а также эко-номических проблем постиндустриального социума к попыткам оценки в этих концептуальных координатах текущей российской реальности.

Повсеместно в становлении общества знаний ныне всё глубже проявляется интеграция усилий вокруг проблемы эффективности. Условием эффективности выступает технологичность: именно с развитием технологий связывают надежды на прогресс в получении нового знания как движущей силы развития современного социума. Такая технологичность объективно подразумевает стремление к минимуму ресурсов, как людских, так и сырьевых, а также финансовых. Что же, - по мнению Иноземцева противостоящее этим подходам, - происходит в России? В нашем национальном «сознании исполнение того или иного проекта самоценно; затраты в данном случае вторичны. Как известно, основой рыночного механизма конкуренции является ограничение издержек. А при отечественном подходе технологические инновации бессмысленны, а невосприимчивость страны к инновациям вполне объяснима» 1 .

В полном соответствии с уже упомянутой традицией рассмотрения современности не только с экономических, но и с социокультурных позиций автору книги приходится констатировать, что «трата средств стала своего рода навязчивой национальной идеей: предполагается, что в ней отражается растущая мощь и возможности государства» ${ }^{2}$. Действительно, показная национальная практика забвения эффективности сегодня абсолютно не согласуется с общемировыми трендами.

В социокультурном измерении в массовом сознании россиян по-прежнему существует и ощущение величия от размеров территории, при этом они продолжают эксплуатироваться экстенсивно. Очевидно, что в эпоху постиндустриального развития подобные территориальные тренды, а также акценты национального развития невозможно считать современными. Здесь трудно не согласиться с профессором Иноземцевым, который замечает, что в современ-ном мире «территория скорее «обязательство», чем актив, т.к. требует развития, а оно - денег»³.

Следуя логике автора книги, практика забвения эффективности проявляет себя как в архаичных технологических стилях обращения с ресурсами, так и в нерациональном отношении не только к территориям, но и к человеческому капиталу и интеллекту, которыми в обозначенной парадигме можно не дорожить, памятуя об их мнимой неисчерпаемости.

Теоретические постулаты постиндустриализма/информационного общества неотделимы от концепта модернити. Исходя их этого, В.Л. Иноземцев предлагает в книге собственное определение модернизации. Оно, безусловно, не является идеальным с точки зрения логических правил построения дефиниций, зато является достаточно простым и наглядным. Автор считает, что «настоящая модернизация - это процесс, лишающий общество потребности в каких бы то ни было последующих модернизациях» ${ }^{4}$.

В социокультурном контексте исследователь формулирует специфику российских модернизаций как хаотичное стремление к «величию» любой ценой, но не нацеленное на движе-ние к «современности». Так весьма специфическим образом в национальных условиях

\footnotetext{
${ }^{1}$ Иноземцев В.Л. Несовременная страна. Россия в мире XXI века. М., 2018. С. 49.

2 Там же. С. 52.

3 Там же. С. 108.

4 Там же. С. 62.
} 
происходит взаимодействие эффективности с модернизацией.

Очень важной, с нашей точки зрения, является представленное в анализируемой книге такое видение модернизации, которое фактически для любого социума ассоциирует её с преодолением. И здесь Россия в эпоху всех своих модернизаций не стала исключением. Однако, как показывает автор, этого недостаточно для результативности последних. Преодоление трудностей в модернизационный период, по мысли В.Л. Иноземцева, всегда должно быть длительным, занимать десятилетия, в течение которых население привыкает именно к такому порядку вещей. Вероятно, истоки национального «нетерпения» и более кратких, чем требуется нашей стране, а значит и незавершённых периодов перемен, было бы любопытно исследовать, но в данной книге читатель не находит подобных размышлений.

Что касается современной России, то для характеристики происходящих в ней процессов, способствующих/или скорее тормозящих прогрессивные изменения, приводятся следующие аргументы:

- сегодня наша страна не имеет устойчиво-неизменных (подчёркнуто мною. - Е.В.) торговых и инвестиционных связей с государством/государствами заметно более высокого уровня экономического развития,

- в стране почти не строится новых промышленных предприятий. «Стоит отметить, замечает автор «Несовременной страны», - глобальная конъюнктура всегда была крайне благоприятна для России, которая реагировала на любые изменения потребностей развитых стран и поставляла (в основном в Европу) всё новые и новые товары - вместо пушнины лес, затем металлы, потом нефть и газ, и всякий раз ресурсная специализация воспроизводилась на более высоком уровне, сопровождаясь при этом последовательным снижением степени обработки экспортируемых товаров» ${ }^{1}$. Естественно снижение глубины переработки прямым путем ведёт к архаике, а не к современности,

- в противовес трендам глобальной экономики с её горизонтальными связями и сетевой организацией в России происходит насаждение опоры на собственные возможности и ориентация на установление тотального контроля центральной власти над основными отраслями и крупнейшими корпорациями. Этот контроль в инновационном плане являет себя весьма специфически, поскольку ожидает коммерчески успешных новинок в слишком крупных, по мне-нию автора книги, отраслях, (например, в ядерной энергетике). Мировая же практика говорит о том, что в отраслях-гигантах инновационные процессы возникают реже и происходят медленнее,

- наконец, только страны, целостно усвоившие прежний (в случае России индустриальный) уклад, могут успешно развивать следующий, (речь идёт о классической постиндустриальной триаде - Е.В.).

Очевидно, что эффективность в любой культуре не является вещью в себе, а коренится в том числе и в ментальных предпосылках. Многочисленные параметры последних автор озвучивает на протяжении всего изложения. Мы отметим здесь лишь два из них, взаимодействие которых оказывается противоречивым. Первый касается процесса некоего, так сказать, перманентного реванша, характеризуемого тем, что «Россия практически постоянно стремится не столько перенять нечто у соседей, сколько “обогнать” их»". Казалось бы, в этом нет ничего плохого, но автор замечает непоследовательность и пугающую незавершённость таких «обгонов», когда уже даже в современной истории страны таких стратегий можно было на-считать не менее пяти. Здесь и цель удвоения ВВП в начале 2000-х, «национальные

\footnotetext{
${ }^{1}$ Там же. С. 47.

${ }^{2}$ Иноземцев В.Л. Несовременная страна. Россия в мире XXI века. М., 2018. С.122. Научно-аналитический вестник ИЕ РАН, 2019, №4
} 
проекты», программы модернизации в 2008-2011 гг. и позиционирование себя в качестве энергетической сверхдержавы.

Второй параметр связан с тем, что при этом фоном для отмеченной фрагментарности безусловно выступает и такой архетип коллективного национального бессознательного как отношение к предпринимательству. Последнее предстаёт не как условие социального прогресса, а как самодовлеющее средство наживы. И коль скоро это в первую очередь так, то ожидать от страны несовременности и неэффективности приходится скорее, нежели реализации правильных деклараций о постиндустриальных перспективах.

Вывод, к которому приходит автор в заключении книги, звучит достаточно неожиданно: «Что должно случиться для того, чтобы страна предпочла современность архаике, я не возьмусь сказать» ${ }^{1}$. На наш взгляд, это, однако, вовсе не означает, что исследователь написал неглубокую книгу, в которой наличествуют лишь оценки, противостоящие рекомендациям. И хотя в ней не прогнозируется будущее России, зато детально и системно исследуется на-стоящее, во многом коренящееся в глубинах отечественной истории. Подобный синтез концепта постиндустриализма с социокультурной методологией, обращённый на российские реалии, представляется весьма эвристичным вне зависимости от того, насколько В.Л. Иноземцеву удаётся убедить вдумчивых читателей в своей правоте.

\section{Список литературы}

Инглхарт Р., Вельцель К. Пересмотренная теория модернизации / Инглхарт Р., Вельцель К. Модернизация, культурные изменения и демократия: Последовательность человеческого развития. М.: Новое издательство, 2011. С. 31-79.

Иноземцев В.Л. Несовременная страна. Россия в мире XXI века. М., Альпина Паблишер., 2018. URL: http://www.litres.ru/pages/biblio book/?art=36633772\&lfrom=30440123 (дата обращения: 15.04.2019).

Inosemzew W. Ukrainischer Fluch, sibirischer Segen: Russlands Regionalismus und seine kolonialen Ursprunge. Osteuropa, Bd. 67, №5, 2017. S. 101-114.

\section{References}

Inglhart R., Vel'cel' K. Peresmotrennaja teorija modernizacii / Inglhart R., Vel'cel' K. Modernizacija, kul'turnye izmenenija i demokratija: Posledovatel'nost' chelovecheskogo razvitija. M., Novoe izdatel'stvo, 2011. S. 31-79.

Inozemcev V.L. Nesovremennaja strana. Rossija v mire XXI veka. M.: Al'pina Pablisher, 2018. URL: http://www.litres.ru/pages/biblio_book/?art=36633772\&lfrom=30440123 (data obrashhenija: 15.04.2019).

Inosemzew W. Ukrainischer Fluch, sibirischer Segen: Russlands Regionalismus und seine kolonialen Ursprunge. Osteuropa, Bd. 67, №5, 2017. S. 101-114.

\section{The Non-Modern Country by Vladislav Inozemtsev}

Author. Elena Vodopianova, Doctor of Sciences (Philosophy), Professor, Senior Researcher, Department of Social and Political Studies, Institute of Europe, Russian Academy of Sciences. Address: 11-3, Mokhovaya str., Moscow, Russia, 125009. E-mail: veritas-41 @ yandex.ru.

\footnotetext{
${ }^{1}$ Там же. С. 125.
} 
Abstract. The author speculates on the contradictory development of Russia in the coordinates of modernity - non-modernity as they are preset by V. Inozemtsev's research, the Founder of the Postindustrial Society Research Center. In solidarity with the author of the book, the paper also focuses on the social, cultural, and economic parameters, which largely inhibit the movement of Russia to the information realities: resource economy, archaic and traditional understanding of the role of territories, of innovative strategies and underdevelopment of the industrial way of life. Reflections on the country's non-modernity are inseparable from the debate with the researcher on the issues related to the definitions and features of national modernizations, beyond which the processes of effective development of modern society and increase of its technological effectiveness in the post-industrial period are impossible.

Key words: Russia, non-modern country, resource economics, efficiency, contradictions of modernity, post-industrialism.

DOI: http://dx.doi.org/10.15211/vestnikieran4201999103 